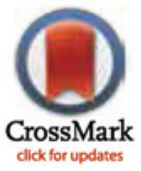

click for updates
RESEARCH ARTICLE

\section{Perceived Stress and Coping Strategies in Relation to Body Mass Index: Cross-Sectional Study of 12,045 Japanese Men and Women}

\author{
Chisato Shimanoe ${ }^{1 *}$, Megumi Hara ${ }^{1}$, Yuichiro Nishida ${ }^{1}$, Hinako Nanri ${ }^{1,2}$, Yasuko Otsuka ${ }^{1}$, \\ Kazuyo Nakamura ${ }^{3}$, Yasuki Higaki ${ }^{4}$, Takeshi Imaizumi ${ }^{1}$, Naoto Taguchi ${ }^{1}$, \\ Tatsuhiko Sakamoto ${ }^{5}$, Mikako Horita ${ }^{1}$, Koichi Shinchi ${ }^{6}$, Keitaro Tanaka ${ }^{1}$ \\ 1 Department of Preventive Medicine, Faculty of Medicine, Saga University, Saga, Japan, 2 Department of \\ Public Health, Showa University School of Medicine, Shinagawa-ku, Tokyo, Japan, 3 St. Mary's College \\ Faculty of Nursing, Kurume, Japan, 4 Laboratory of Exercise Physiology, Faculty of Sports and Health \\ Science, Fukuoka University, Fukuoka, Japan, 5 Chikushi Office for Health, Human Services and \\ Environmental Issues, Fukuoka Prefectural Government, Onojo, Japan, 6 Division of International Health \\ and Nursing, Faculty of Medicine, Saga University, Saga, Japan \\ * chisatos@cc.saga-u.ac.jp
}

\section{G open access}

Citation: Shimanoe C, Hara M, Nishida Y, Nanri H, Otsuka Y, Nakamura K, et al. (2015) Perceived Stress and Coping Strategies in Relation to Body Mass Index: Cross-Sectional Study of 12,045 Japanese Men and Women. PLOS ONE 10(2): e0118105. doi:10.1371/journal.pone.0118105

Academic Editor: Keitaro Matsuo, Kyushu University Faculty of Medical Science, JAPAN

Received: June 9, 2014

Accepted: November 25, 2014

Published: February 12, 2015

Copyright: $\odot 2015$ Shimanoe et al. This is an open access article distributed under the terms of the Creative Commons Attribution License, which permits unrestricted use, distribution, and reproduction in any medium, provided the original author and source are credited.

Data Availability Statement: The authors confirm that, for approved reasons, some access restrictions apply to the data underlying the findings. Data from the "Japan Multi-Institutional Collaborative Cohort Study in Saga region" are not publicly available due to participants' privacy concerns. Individuals seeking access may contact at Dr. Keitaro Tanaka (tanakake@cc.saga-u.ac.jp), Saga University Faculty of Medicine, and the J-MICC Study Central Office: http://www.jmicc.com/en/.

Funding: This work was supported by Grants-in-Aid for Scientific Research on the Special Priority Areas

\section{Abstract}

\section{Background}

Accumulated evidence suggests a weak positive relationship between psychosocial stress and body mass index (BMI), but little is known about stress coping strategies and BMI.

\section{Objective}

We aimed to examine if perceived stress and coping strategies are related to BMI, with any of their mutual interactions on BMI.

\section{Methods}

This cross-sectional study included 5,063 men and 6,982 women aged 40-69 years. A selfadministered questionnaire ascertained perceived stress and 5 items of coping strategies (emotion expression, emotional support seeking, positive reappraisal, problem solving, and disengagement). Analyses were performed by gender with adjustment for age, socioeconomic status, and lifestyle factors.

\section{Results}

No significant associations were detected between perceived stress and BMI in either men $\left(P_{\text {trend }}=0.09\right)$ or women $\left(P_{\text {trend }}=0.58\right)$. In men, however, 'disengagement' showed an inverse association with BMI $\left(P_{\text {trend }}<0.001\right)$, and 'positive reappraisal' and 'problem solving' revealed a positive association with BMI ( $P_{\text {trend }}=0.04$ and 0.007 , respectively) even after controlling for perceived stress. A possible interaction between perceived stress and 'disengagement' on BMI was found in men ( $P_{\text {interaction }}=0.027$ ); the inverse association between 'disengagement' and BMI was more evident in higher levels of stress $(\beta=-0.13$, $P_{\text {trend }}=0.21$ in low; $\beta=-0.22, P_{\text {trend }}=0.01$ in medium; and $\beta=-0.24, P_{\text {trend }}=0.06$ in high). 
of Cancer (No. 17015018) and Innovative Areas (No. 221S0001); Scientific Research (A) (No. 20249038) and (B) (No. 18390182); and Young Scientists (A) (No. 20689014) and (B) (No. 18790380) from the Ministry of Education, Culture, Sports, Science and Technology, Japan. The funders had no role in study design, data collection and analysis, decision to publish, or preparation of the manuscript.

Competing Interests: The authors have declared that no competing interests exist.
In men, 'disengagement' was inversely associated with overweight/obesity (odds ratio 0.79 , 95\% confidential interval 0.67-0.95), and "positive reappraisal" was positively associated with it $(1.25,1.02-1.54)$.

\section{Conclusions}

Coping strategies may have an important role in developing overweight/obesity, particularly in men.

\section{Introduction}

Psychosocial factors have been independently associated with cardiovascular diseases (CVD) [1] although they have shown weaker associations than other established risk factors such as smoking and obesity [2]. Psychosocial stress may lead to CVD possibly through developing obesity[3], and thus its association with indices of adiposity including the body mass index (BMI) have been investigated [4,5]. In a recent meta-analysis of 14 longitudinal studies on psychosocial stress and adiposity (evaluated mostly with BMI), the majority (69\%) of correlation coefficients ( $r$ ) revealed no significant relationships, followed by significant positive associations $(25 \%)$ and significant inverse ones $(6 \%)$, with an overall very weak positive association (combined $r=0.014,95 \%$ confidence interval 0.002-0.025) [4]. Additional two longitudinal studies suggested a positive association [6] or no association [7] whereas two large cross-sectional studies demonstrated a weak positive association [5,8]. Accordingly, the overall evidence appears to support a positive association between psychosocial stress and BMI although the magnitude of the association is very weak.

The individuals' efforts to manage stressors, coping strategies [9], have been conceptualized as moderators of the association between psychosocial stress and health-related outcomes [10]. Excess cortisol secretion is considered to be one of the mechanisms for the relationship between psychosocial stress and weight gain [11], and one recent study indicated that the lack of a coping strategy (i.e., each of self-protection, problem engagement, and seeking social support) was associated with elevated glucocorticoids $[12,13]$. We therefore hypothesized that coping strategies may be potential predictors of obesity as well as moderators of the link between stress and obesity. To our knowledge, only one study suggested an inverse association between a coping strategy (i.e., confrontive coping) and BMI in 180 women [14], and little is known about whether coping strategies moderate the association between psychosocial stress and BMI, or vice versa. The impact of gender difference on the association between coping strategies and BMI may also be of concern due to the paucity of such data.

We conducted a cross-sectional study of a middle-aged and older general Japanese population in order to examine if perceived stress and coping strategies are related to BMI, with any mutual interactions and gender differences in their possible relations to BMI.

\section{Methods}

\section{Study population}

The Japan Multi-Institutional Collaborative Cohort Study (J-MICC Study) was initiated in 2005 with the aim of obtaining fundamental data for the prevention of life-style related diseases, mainly cancer, according to genetic traits $[15,16]$. As part of participants in the baseline survey of the J-MICC Study between 2005 and 2007, we enrolled 12,078 men and women who 
were aged 40-69 years and resident in Saga city, Japan [17-19]. Ten subjects withdrew later, and the remaining 12,068 subjects constituted the study population of this cross-sectional study. Baseline measures included height $(\mathrm{cm})$, weight $(\mathrm{kg})$, socioeconomic status (SES: occupation, working hours, and years of schooling), lifestyle factors (alcohol consumption, smoking, physical activity, sleeping hours, and energy intake), and psychosocial factors (perceived stress and coping strategies). The subjects completed a self-administered questionnaire, and any missing or inconsistent answers were checked by a research nurse at the survey location.

All subjects gave written informed consent, and the study protocol was approved by the ethics committees at both Saga University Faculty of Medicine and Nagoya University Graduate School of Medicine.

\section{Perceived stress and Coping strategies}

Perceived mental stress in daily life was assessed by a single question $[19,20]$, "How much stress did you feel during the last year?" Four response categories were given as: 1) "I felt much stress", 2) "I felt moderate stress", 3) “I felt little stress", and 4) “I felt no stress at all.” The perceived stress level was regarded as high for the response category 1); medium for the category 2 ); and low for the categories 3) and 4) combined. We assigned scores of 1-3 to low, medium, and high levels of perceived stress, respectively. The weighted $\kappa$ for this question in a 1-year reproducibility survey on a random sample $(n=431)$ was 0.55 [19], which was analogous to that reported in the INTERHEART study (Cohen's $\kappa=0.5)$ [1].

For coping strategies, we used 5 items selected from a dispositional version of the General Coping Questionnaire [21,22] or the brief COPE [23]. These coping strategies were evaluated as follows. After a query, "How do you cope with various problems and unfavorable events you experience in daily life?", subjects were requested to answer the frequency (four response categories: "seldom", "sometimes", "often", and "very often") of each of the following coping strategies: 1) "I express my negative feelings and thoughts" (termed 'emotion expression'), 2) "I consult with someone close and ask him/her for encouragement" (termed 'emotional support seeking' [ESS]), 3) "I try to interpret the problem in a favorable way" (termed 'positive reappraisal'), 4) "I try hard to solve the problem" (termed 'problem solving'), and 5) "I let the problem take its own course" (termed 'disengagement'). The level of each coping strategy was classified as low for the frequency of "seldom", medium for "sometimes", and high for "often" or "very often". The weighted $\kappa$ in the reproducibility survey ranged from 0.30 to 0.55 for these coping strategies [19].

\section{Covariates}

Occupation, working hours (including those for housework), and years of schooling were considered as indicators of SES. Subjects' occupation at the baseline survey was asked in an openended manner, and their responses were classified according to the International Standard Classification of Occupations, 2008 (ISCO-08) into 4 categories: 0-2 (armed forces occupations, managers, and professionals); $3-5$ (technicians, associate professionals, clerical support workers, and service and sales workers); 6-9 (skilled agricultural, forestry and fishery workers, craft and related trades workers, plant and machine operators, assemblers, and elementary occupations); and unemployed subjects including retired persons and housewives. Years of schooling were estimated based on the school from which subjects graduated.

Lifestyle factors included drinking and smoking habits, physical activity, sleeping hours, and energy intake. Total ethanol consumption (g/day) was estimated from reported consumption frequencies and amounts of 6 types of alcoholic beverages. Physical activity was assessed with a single-axis accelerometer [24] (Kenz Lifecorder Ex; Suzuken Co., Ltd., Nagoya, Japan) worn by subjects for 10 days after the baseline survey. The physical activity level was calculated 
as total energy expenditure (kcal/day) divided by basal metabolic rate ( $\mathrm{kcal} /$ day); the former was estimated from the accelerometer as average daily energy expenditure (excluding the initial 3 days), and the latter was defined as basal metabolism standard [25] $\times$ body surface area [26] $\times 24$ hours. Total energy intake was estimated using the information from a validated short food frequency questionnaire [27,28] and standard tables of food composition in Japan (Fifth Revised Edition) [29] as previously described [18].

\section{Statistical analysis}

From among the 12,068 participants in the baseline survey, we excluded 23 subjects who had missing data on perceived stress or BMI $(n=19)$, or a dietary energy intake greater than 4000 $\mathrm{kcal} /$ day $(\mathrm{n}=4)$. Consequently, 12,045 subjects $(5,063$ men and 6,982 women) remained for this study. All analyses were performed separately for men and women with the SAS statistical software package (Ver. 9.3 for Windows; SAS Institute, Cary, NC, USA).

The differences of baseline characteristics by BMI levels $\left(<25\right.$ and $\left.\geq 25 \mathrm{~kg} / \mathrm{m}^{2}\right)$ in men or women were tested by $t$ tests (for continuous variables) or chi-square tests (for categorical variables). The associations of perceived stress and 5 coping strategies (each 3 categories [low, medium, and high] converted to an ordinal variable) with BMI $\left(\mathrm{kg} / \mathrm{m}^{2}\right)$ were evaluated by simple and multiple liner regression analyses. Covariates for 1) age (years), 2) SES (occupation [4 categories by ISCO -08 as described above], working hours [ 4 categories: $<5, \geq 5-<7, \geq 7-<9$, and $\geq 9$ ], and years of schooling [5 categories: $\leq 9,12,14,16$, and $\geq 17]$ ), 3) lifestyle factors (drinking [ 5 categories: never, former, and current drinker consuming 0.1-22.9, 23.0-45.9, and $\geq 46 \mathrm{~g}$ ethanol/day], smoking [ 5 categories: never, former, and current smoker consuming $1-19,20-39$, and $\geq 40$ cigarettes/day], physical activity level [continuous], sleeping hours [ 4 categories: $<6, \geq 6-<7, \geq 7-<8$, and $\geq 8$ ], and total energy intake [kcal/day]), and 4) either perceived stress (for each of coping strategies as a main variable) or all coping strategies (for perceived stress as a main variable) were added to the model in a stepwise manner. A linear trend of the association of each of perceived stress and coping strategies with BMI was assessed by the statistical significant of the corresponding regression coefficient. Gender differences of regression coefficients were tested using the model for both genders combined, with an additional interaction term for each psychosocial variable and gender. Whether the association between each coping strategy and BMI varied by occupation (4 categories) or perceived stress levels (low, medium, and high) was examined in stratified analysis, and was tested by including in the model additional interaction term(s) for either occupation (categorical variable) or perceived stress (ordinal variable) and each coping strategy (ordinal variable). Adjusted means of BMI and their $95 \%$ confidence intervals (CIs) by the level of each coping strategy were computed as least square means (i.e., analysis of covariance) by using the GLM procedure with the LSMEANS statement and the OBSMARGINS option in SAS.

Multiple logistic regression analyses were applied to estimate adjusted odds ratios and their $95 \%$ CIs of overweight/obesity $\left(\mathrm{BMI} \geq 25.0 \mathrm{~kg} / \mathrm{m}^{2}\right)$ [30] for each of perceived stress and coping strategies. All $P$ values reported are two-tailed, and those values less than 0.05 were considered statistically significant.

\section{Results}

Table 1 shows baseline characteristics of the study subjects with and without overweight/obesity $\left(B M I \geq 25.0 \mathrm{~kg} / \mathrm{m}^{2}\right)$ stratified by gender. Men with overweight/obesity were significantly more likely to be younger, use some coping strategies (positive reappraisal and problem solving), have managerial and professional occupations, and sleep shorter, as compared to those without overweight/obesity. Women with overweight/obesity, as compared to those without it, 
Table 1. Characteristics of study subjects (5,063 men and 6,982 women) by body mass index (BMI, $<25$ and $\left.\geq 25 \mathrm{~kg} / \mathrm{m}^{2}\right)-\mathrm{Japan}, 2005-2007$.

\begin{tabular}{|c|c|c|c|c|c|c|}
\hline \multirow[t]{2}{*}{ Characteristic } & \multicolumn{2}{|c|}{ Men } & \multirow[t]{2}{*}{$P^{a}$} & \multicolumn{2}{|c|}{ Women } & \multirow[t]{2}{*}{$P^{a}$} \\
\hline & BMI $<25(n=3,487)$ & $B M I \geq 25(n=1,576)$ & & BMI $<25(n=5,699)$ & $B M I \geq 25(n=1,283)$ & \\
\hline BMI $\left(\mathrm{kg} / \mathrm{m}^{2}\right)$ & $22.2(1.9)$ & $27.1(2.1)$ & - & $21.2(2.1)$ & $27.5(2.5)$ & - \\
\hline Underweight (< $\left.18.5 \mathrm{~kg} / \mathrm{m}^{2}, \%\right)$ & 4.3 & - & & 9.7 & - & \\
\hline Obesity ( $\left.\geq 30 \mathrm{~kg} / \mathrm{m}^{2}, \%\right)$ & - & 9.0 & & - & 13.4 & \\
\hline Age (years) & $56.8(8.2)$ & $56.0(8.2)$ & $<0.01$ & $55.3(8.3)$ & $56.9(7.9)$ & $<0.01$ \\
\hline Perceived stress ( $\%$ of high level ${ }^{\mathrm{b}}$ ) & 29.1 & 29.6 & 0.43 & 18.1 & 20.0 & 0.02 \\
\hline \multicolumn{7}{|l|}{ Coping strategies (\% of high level ${ }^{c}$ ) } \\
\hline Emotion expression & 20.0 & 21.6 & 0.18 & 18.4 & 17.6 & 0.51 \\
\hline Emotional support seeking & 8.3 & 9.5 & 0.17 & 29.8 & 26.5 & 0.02 \\
\hline Positive reappraisal & 51.0 & 54.8 & 0.01 & 57.6 & 61.1 & 0.33 \\
\hline Problem solving & 59.0 & 63.5 & $<0.01$ & 54.8 & 55.1 & 0.87 \\
\hline Disengagement & 30.1 & 28.3 & 0.18 & 36.8 & 37.3 & 0.75 \\
\hline Occupation (ISCO-08 $\left.{ }^{\mathrm{d}}, \%\right)$ & & & $<0.01$ & & & 0.03 \\
\hline $0-2$ & 35.2 & 43.9 & & 17.2 & 15.8 & \\
\hline $3-5$ & 27.9 & 25.1 & & 30.6 & 27.9 & \\
\hline $6-9$ & 17.8 & 15.5 & & 9.7 & 11.4 & \\
\hline Unemployed & 19.2 & 15.5 & & 42.5 & 44.9 & \\
\hline Working hours $\geq 9(\%)$ & 37.7 & 36.3 & 0.36 & 29.5 & 24.0 & $<0.01$ \\
\hline Years of schooling $\geq 12(\%)$ & 49.4 & 49.1 & 0.46 & 42.2 & 33.6 & $<0.01$ \\
\hline Current drinker (\%) & 79.4 & 79.1 & 0.80 & 42.4 & 37.1 & $<0.01$ \\
\hline Current smoker (\%) & 36.4 & 35.5 & 0.51 & 8.5 & 8.1 & 0.95 \\
\hline Physical activity level ${ }^{\mathrm{e}}$ & $1.45(0.09)$ & $1.45(0.09)$ & 0.36 & $1.46(0.08)$ & $1.47(0.09)$ & 0.007 \\
\hline Sleeping hours & $6.9(0.98)$ & $6.7(1.00)$ & $<0.01$ & $6.5(0.93)$ & $6.5(0.98)$ & 0.99 \\
\hline Energy intake (kcal/day) & $1935(340)$ & $1938(369)$ & 0.81 & $1514(227)$ & $1520(243)$ & 0.42 \\
\hline
\end{tabular}

Data are mean (standard deviation) or percentage.

a $\mathrm{P}$ values for the difference by BMI ( $<25$ and $\geq 25 \mathrm{~kg} / \mathrm{m}^{2}$ ) based on $\mathrm{t}$ test (for continuous variables) or $\mathrm{X}^{2}$ test (for categorical variables).

${ }^{\mathrm{b}}$ High level represents having felt 'much' stress for the last year.

' High level represents the frequency of 'often' or 'very often' for each coping strategy.

d Based on the International Standard Classification of Occupation 2008 (see the "Methods"). The "unemployed" category includes retired subjects and housewives.

e Calculated as total energy expenditure (kcal/day) divided by basal metabolic rate (kcal/day).

doi:10.1371/journal.pone.0118105.t001

were older, felt more stress, used emotional support seeking less frequently, worked shorter, had lower education, included fewer drinkers, and had higher physical activity levels.

Perceived stress had significant positive correlations with emotion expression, ESS, and problem solving (Table 2). Perceived stress also showed a weak inverse association with disengagement in women, but not in men. As shown in Table 2, higher levels of stress and all coping strategies were associated with younger age in both men and women. Perceived stress and coping strategies were mostly positively correlated with employment, working hours, years of schooling, and alcohol drinking. Only perceived stress and emotion expression showed a positive correlation with smoking. Perceived stress was inversely related to sleeping hours. In men, higher levels of perceived stress and all coping strategies were associated with higher energy intake.

Table 3 shows the associations of perceived stress and coping strategies with BMI by gender. In men, BMI tended to increase with positive reappraisal and problem solving $\left(P_{\text {trend }}: 0.001\right.$ 
Table 2. Spearman's rank correlation coefficients between psychosocial factors/body mass index and covariates by gender-Japan, $2005-2007$.

\begin{tabular}{|c|c|c|c|c|c|c|c|c|c|c|}
\hline & $\begin{array}{l}\text { Perceived } \\
\text { stress }\end{array}$ & Age & Unemployed $^{a}$ & $\begin{array}{l}\text { Working } \\
\text { hours }\end{array}$ & $\begin{array}{l}\text { Years of } \\
\text { schooling }\end{array}$ & Drinking & Smoking & $\begin{array}{l}\text { Physical } \\
\text { activity } \\
\text { level }^{\mathbf{b}}\end{array}$ & $\begin{array}{l}\text { Sleeping } \\
\text { hours }\end{array}$ & $\begin{array}{l}\text { Energy } \\
\text { intake }\end{array}$ \\
\hline \multicolumn{11}{|l|}{$\operatorname{MEN}(n=5,063)$} \\
\hline Perceived stress & - & -0.30 & -0.21 & 0.28 & 0.12 & 0.02 & 0.06 & -0.01 & -0.14 & 0.03 \\
\hline $\begin{array}{l}\text { Emotion } \\
\text { expression }\end{array}$ & 0.13 & -0.05 & $<0.01$ & 0.01 & 0.01 & 0.06 & 0.04 & $<0.01$ & $<0.01$ & 0.06 \\
\hline $\begin{array}{l}\text { Emotional support } \\
\text { seeking }\end{array}$ & 0.15 & -0.17 & -0.09 & 0.09 & 0.06 & 0.03 & 0.01 & 0.03 & -0.02 & 0.08 \\
\hline $\begin{array}{l}\text { Positive } \\
\text { reappraisal }\end{array}$ & -0.02 & -0.06 & -0.07 & 0.07 & 0.08 & 0.04 & $<0.01$ & 0.01 & $<0.01$ & 0.03 \\
\hline Problem solving & 0.10 & -0.11 & -0.11 & 0.13 & 0.10 & 0.04 & $<0.01$ & 0.04 & -0.03 & 0.04 \\
\hline Disengagement & 0.02 & -0.08 & -0.05 & 0.04 & 0.04 & $<0.01$ & -0.02 & -0.01 & -0.04 & 0.04 \\
\hline Body mass index & $<.001$ & -0.04 & -0.05 & 0.02 & 0.02 & 0.03 & -0.01 & 0.04 & -0.08 & $<0.01$ \\
\hline \multicolumn{11}{|l|}{$\begin{array}{l}\text { WOMEN }(n= \\
6,982)\end{array}$} \\
\hline Perceived stress & - & -0.21 & -0.12 & 0.19 & 0.10 & 0.06 & 0.07 & -0.01 & -0.14 & -0.01 \\
\hline $\begin{array}{l}\text { Emotion } \\
\text { expression }\end{array}$ & 0.13 & -0.11 & $<0.01$ & 0.02 & 0.05 & 0.04 & 0.03 & -0.08 & $<0.01$ & 0.03 \\
\hline $\begin{array}{l}\text { Emotional support } \\
\text { seeking }\end{array}$ & 0.18 & -0.23 & -0.07 & 0.06 & 0.11 & 0.04 & $<0.01$ & 0.05 & -0.04 & 0.03 \\
\hline $\begin{array}{l}\text { Positive } \\
\text { reappraisal }\end{array}$ & -0.02 & -0.03 & -0.05 & 0.05 & 0.08 & 0.03 & $<0.01$ & 0.02 & -0.03 & 0.02 \\
\hline Problem solving & 0.10 & -0.08 & -0.05 & 0.08 & 0.09 & 0.03 & 0.01 & 0.02 & -0.04 & 0.01 \\
\hline Disengagement & -0.03 & -0.06 & -0.02 & 0.02 & 0.01 & $<0.01$ & 0.01 & 0.01 & $<0.01$ & 0.03 \\
\hline Body mass index & -0.05 & 0.16 & 0.04 & -0.09 & -0.09 & -0.03 & -0.01 & 0.07 & 0.02 & 0.01 \\
\hline
\end{tabular}

doi:10.1371/journal.pone.0118105.t002

and $<0.001$, respectively) and to decrease with disengagement $\left(P_{\text {trend }}=0.016\right)$. In women, BMI decreased with perceived stress, emotion expression, and ESS $\left(P_{\text {trend }}:<0.001,0.016\right.$, and $<0.001$, respectively). In age-adjusted analysis for men, BMI increased with positive reappraisal and problem solving ( $P_{\text {trend }} 0.002$ and $<0.001$, respectively) and decreased with disengagement $\left(P_{\text {trend }}=0.006\right)$. These associations remained significant after adjustment for SES $\left(P_{\text {trend: }}\right.$ $0.02,0.006$ and 0.01 , respectively) (Table 3, Model 1$)$ and lifestyle factors $\left(P_{\text {trend }}: 0.03,0.009\right.$ and 0.001 , respectively) (Table 3, Model 2), as well as perceived stress or coping strategies ( $P_{\text {trend }}: 0.04,0.007$ and $<0.001$, respectively) (Table 3, Model 3). In contrast, the univariate associations of perceived stress, emotion expression, and ESS with BMI in women became insignificant after adjustment for age and other factors. In fully adjusted analyses of men and women combined, which correspond to Model 3 in Table 3, there was evidence for gender heterogeneity (i.e., difference between regression coefficients in both genders) in the associations of perceived stress $\left(P_{\text {interaction }}=0.004\right)$, ESS $\left(P_{\text {interaction }}=0.006\right)$, positive reappraisal $\left(P_{\text {interaction }}\right.$ $=0.003)$, problem solving $\left(P_{\text {interaction }}=0.004\right)$, and disengagement $\left(P_{\text {interaction }}=0.027\right)$ with BMI (data not shown).

In additional analyses stratified by the covariates, we noted some differences by occupation in the above associations of problem solving and disengagement with BMI in men (Table 4). 
Table 3. Regression analyses for the associations of perceived stress and coping strategies with body mass index by gender-Japan, 20052007.

\begin{tabular}{|c|c|c|c|c|c|c|c|c|c|c|}
\hline & \multicolumn{2}{|c|}{ Crude } & \multicolumn{2}{|c|}{ Age-adjusted } & \multicolumn{2}{|c|}{ Model $1^{a}$} & \multicolumn{2}{|c|}{ Model $2^{b}$} & \multicolumn{2}{|c|}{ Model $3^{c}$} \\
\hline & $\beta$ (SE) & $P_{\text {trend }}$ & $\beta$ (SE) & $P_{\text {trend }}{ }^{d}$ & $\beta$ (SE) & $P_{\text {trend }}^{d}$ & $\beta$ (SE) & $P_{\text {trend }}{ }^{d}$ & $\beta$ (SE) & $P_{\text {trend }}{ }^{d}$ \\
\hline \multicolumn{11}{|l|}{$\operatorname{Men}(n=5,063)$} \\
\hline Perceived stress & $0.01(.06)$ & 0.93 & $-0.07(.06)$ & 0.26 & $-0.09(.06)$ & 0.13 & $-0.12(.06)$ & 0.06 & $-0.11(.06)$ & 0.09 \\
\hline Emotion expression & $-0.01(.07)$ & 0.89 & $-0.02(.07)$ & 0.75 & $-0.03(.07)$ & 0.64 & $-0.06(.07)$ & 0.40 & $-0.04(.07)$ & 0.53 \\
\hline Emotional support seeking & $0.06(.07)$ & 0.34 & $0.02(.06)$ & 0.75 & $0.01(.07)$ & 0.90 & $0.02(.07)$ & 0.81 & $0.03(.07)$ & 0.69 \\
\hline Positive reappraisal & $0.20(.06)$ & 0.001 & $0.19(.07)$ & 0.002 & $0.15(.06)$ & 0.02 & $0.13(.06)$ & 0.03 & $0.12(.06)$ & 0.04 \\
\hline Problem solving & $0.25(.06)$ & $<0.001$ & $0.22(.07)$ & $<0.001$ & $0.18(.07)$ & 0.006 & $0.17(.07)$ & 0.009 & $0.18(.07)$ & 0.007 \\
\hline Disengagement & $-0.15(.06)$ & 0.016 & $-0.17(.06)$ & 0.006 & $-0.15(.06)$ & 0.01 & $-0.20(.06)$ & 0.001 & $-0.20(.06)$ & $<0.001$ \\
\hline \multicolumn{11}{|l|}{ Women $(n=6,982)$} \\
\hline Perceived stress & $-0.21(.06)$ & $<0.001$ & $-0.08(.06)$ & 0.14 & $-0.04(.06)$ & 0.44 & $-0.04(.06)$ & 0.51 & $-0.03(.05)$ & 0.58 \\
\hline Emotion expression & $-0.16(.07)$ & 0.016 & $-0.08(.07)$ & 0.22 & $-0.08(.07)$ & 0.21 & $-0.08(.07)$ & 0.21 & $-0.08(.07)$ & 0.22 \\
\hline Emotional support seeking & $-0.19(.05)$ & $<0.001$ & $0.06(.06)$ & 0.31 & $-0.05(.06)$ & 0.35 & $-0.03(.06)$ & 0.56 & $-0.03(.06)$ & 0.62 \\
\hline Positive reappraisal & $0.07(.06)$ & 0.25 & $-0.04(.07)$ & 0.48 & $-0.01(.06)$ & 0.91 & $-0.02(.06)$ & 0.72 & $-0.02(.06)$ & 0.69 \\
\hline Problem solving & $-0.06(.06)$ & 0.36 & $0.01(.06)$ & 0.92 & $0.05(.06)$ & 0.41 & $0.04(.06)$ & 0.48 & $0.05(.06)$ & 0.44 \\
\hline Disengagement & $0.02(.06)$ & 0.79 & $0.06(.06)$ & 0.33 & $0.06(.06)$ & 0.33 & $0.06(.06)$ & 0.27 & $0.06(.06)$ & 0.30 \\
\hline
\end{tabular}

Abbreviations: $\beta$, regression coefficient; SE, standard error. The multiple regression models included body mass index $\left(\mathrm{kg} / \mathrm{m}^{2}\right)$ as a dependent variable and each of perceived stress and coping strategies as an ordinal variable (1-3 assigned to low, medium, and high levels, respectively).

The unit of $\beta$ and SE is $\mathrm{kg} / \mathrm{m}^{2}$.

${ }^{\text {a }}$ Adjusted for age and socio-economic status (occupation, working hours, and years of schooling).

${ }^{\mathrm{b}}$ Adjusted for covariates in Model 1 and lifestyle factors (drinking, smoking, physical activity level, sleeping hours, and energy intake).

${ }^{c}$ Adjusted for covariates in Model 2 and either perceived stress (for each of coping strategies) or all coping strategies (for perceived stress).

${ }^{d}$ Represents the statistical significance of $\beta$. 
Table 4. Adjusted means ${ }^{a}$ (and $95 \%$ confidence intervals) of body mass index $\left(\mathrm{kg} / \mathrm{m}^{2}\right)$ by selected coping strategies and occupation in 5,063 men-Japan, 2005-2007.

\begin{tabular}{|c|c|c|c|c|c|}
\hline \multirow[t]{2}{*}{ Coping strategy } & \multicolumn{4}{|c|}{ Occupation $^{b}$} & \multirow[t]{2}{*}{$P_{\text {interaction }}{ }^{c}$} \\
\hline & $0-2$ & $3-5$ & $6-9$ & Unemployed & \\
\hline Positive reappraisal & & & & & 0.98 \\
\hline Low & $23.8(23.4-24.3)$ & $23.5(24.0-23.7)$ & $23.3(22.8-23.8)$ & $23.3(22.8-23.8)$ & \\
\hline Medium & $24.0(23.8-24.2)$ & $23.5(23.2-23.7)$ & $23.4(23.0-23.7)$ & $23.2(22.9-23.5)$ & \\
\hline \multirow[t]{2}{*}{ High } & $24.1(24.0-24.3)$ & 23.7 (23.5-23.9) & $23.4(23.1-23.7)$ & $23.4(23.2-23.7)$ & \\
\hline & $P_{\text {trend }}{ }^{\mathrm{d}}=0.18$ & $P_{\text {trend }}=0.27$ & $P_{\text {trend }}=0.82$ & $P_{\text {trend }}=0.38$ & \\
\hline Problem solving & & & & & 0.25 \\
\hline Low & $23.4(22.8-24.1)$ & $23.6(22.9-24.1)$ & $23.3(22.7-23.8)$ & $23.6(23.2-24.2)$ & \\
\hline Medium & $23.9(23.7-24.2)$ & $23.5(23.2-23.8)$ & $23.1(22.8-23.4)$ & $23.0(22.7-23.4)$ & \\
\hline \multirow[t]{2}{*}{ High } & $24.2(24.0-24.3)$ & 23.7 (23.4-23.9) & $23.5(23.3-23.9)$ & $23.4(23.1-23.7)$ & \\
\hline & $P_{\text {trend }}=0.02$ & $P_{\text {trend }}=0.39$ & $P_{\text {trend }}=0.08$ & $P_{\text {trend }}=0.91$ & \\
\hline Disengagement & & & & & 0.07 \\
\hline Low & $24.4(24.1-24.7)$ & $23.7(23.3-24.1)$ & $23.6(23.2-24.1)$ & $23.6(23.3-24.1)$ & \\
\hline Medium & $24.1(23.9-24.3)$ & $23.5(23.2-23.7)$ & $23.5(23.2-23.8)$ & $23.1(22.9-23.4)$ & \\
\hline \multirow[t]{2}{*}{ High } & $23.8(23.5-24.0)$ & $23.8(23.5-24.0)$ & $23.0(22.6-23.3)$ & 23.2 (22.9-23.6) & \\
\hline & $P_{\text {trend }}=0.002$ & $P_{\text {trend }}=0.63$ & $P_{\text {trend }}=0.009$ & $P_{\text {trend }}=0.14$ & \\
\hline
\end{tabular}

\footnotetext{
${ }^{\text {a }}$ Adjusted for age, socio-economic status (working hours, and years of schooling), lifestyle factors (alcohol consumption, smoking, physical activity level, sleeping hours, and energy intake), and perceived stress.

${ }^{\mathrm{b}}$ Based on the International Standard Classification of Occupation 2008 as follows: 0-2 (armed forces occupations, managers, and professionals); 3-5 (technicians, associate professionals, clerical support workers, and service and sales workers); 6-9 (skilled agricultural, forestry and fishery workers, craft and related trades workers, plant and machine operators, assemblers, and elementary occupations); and unemployed subjects including retired persons and housewives.

${ }^{c}$ Interaction between each coping strategy (ordinal) and occupation (categorical) on body mass index (continuous).

${ }^{\mathrm{d}}$ Based on multiple linear regression analysis including in the model an ordinal variable for each coping strategy (1-3 assigned to low, medium, and high levels, respectively).
}

men were found to be statistically insignificant (odds ratio for high vs. low level $=1.15,95 \% \mathrm{CI}$ $0.91-1.46)$ although the test for linear trend showed statistical significance $\left(P_{\text {trend }}=0.03\right)$.

\section{Discussion}

In the present study, perceived stress was not significantly associated with BMI in either men or women. Instead, we observed that, in men, positive reappraisal and problem solving had a positive association with BMI, and disengagement revealed an inverse association with it even after controlling for perceived stress and other covariates. The associations of problem solving and disengagement with BMI tended to be modified by perceived stress levels, as indicated by a clearer association at higher levels of perceived stress. To examine the clinical relevance of the above findings, we also carried out multiple logistic regression analyses with overweight/obesity as a dependent variable and found that the high level of either positive reappraisal or disengagement was significantly and independently associated with overweight/obesity in men (odds ratios for high vs. low level: 1.25 and 0.79 , respectively).

The overall evidence appears to suggest a weak positive association between psychosocial stress and adiposity [4]. Although we could not find any significant positive association between perceived stress and BMI in either gender, this finding is not necessarily inconsistent with previous results as reviewed in a recent meta-analysis showing that null results were most 

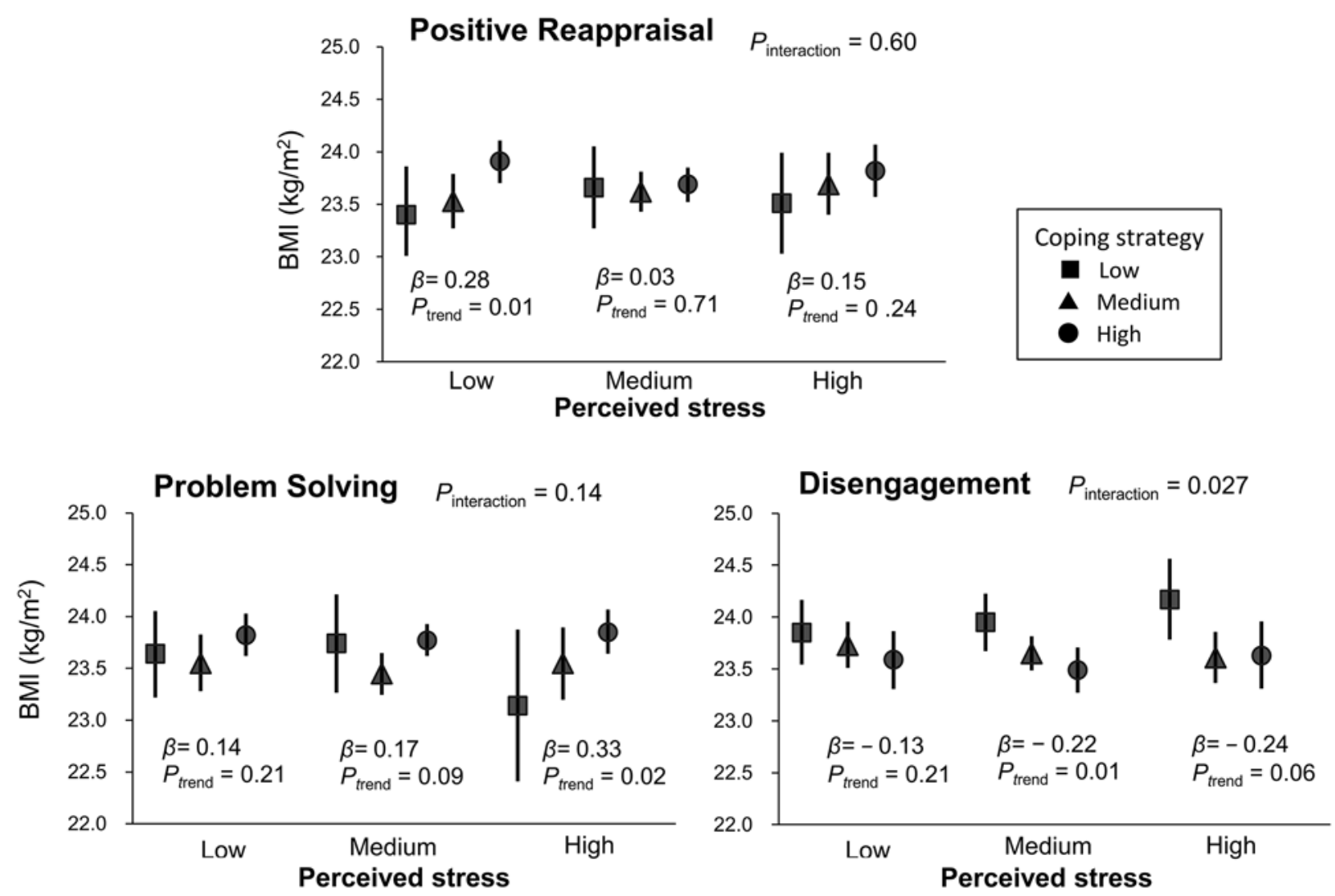

Fig 1. Adjusted means of body mass index (BMI) by levels of selected coping strategies and by perceived stress levels in men. $\beta$ represent regression coefficients in $\mathrm{kg} / \mathrm{m}^{2}$. Adjustment was made for age, socio-economic status (occupation, working hours, and years of schooling), and lifestyle factors (drinking, smoking, physical activity level, sleeping hours, and energy intake). P values for trend were estimated from multiple linear regression analysis including in the model an ordinal variable (1-3 assigned to low, medium, and high levels, respectively) for each coping strategy. Symbols show means and error bars represent $95 \%$ confidential intervals.

doi:10.1371/journal.pone.0118105.g001 
Table 5. Adjusted odds ratios ${ }^{a}$ (and $95 \%$ confidence intervals) of overweight/obesity (body mass index $\geq 25 \mathrm{~kg} / \mathrm{m}^{2}$ ) for each of perceived stress and coping strategies by gender-Japan, 2005-2007.

\begin{tabular}{|c|c|c|c|c|}
\hline & \multicolumn{3}{|c|}{ Level of stress or coping strategy } & \multirow[b]{2}{*}{$P_{\text {trend }} \mathrm{b}$} \\
\hline & Low & Medium & High & \\
\hline \multicolumn{5}{|l|}{ Men $(n=5,063)$} \\
\hline Perceived stress & 1 (reference) & $0.92(0.79-1.07)$ & $0.93(0.77-1.11)$ & 0.40 \\
\hline Emotion expression & 1 (reference) & $0.86(0.73-1.01)$ & $0.92(0.75-1.13)$ & 0.47 \\
\hline Emotional support seeking & 1 (reference) & $0.96(0.84-1.09)$ & $1.08(0.86-1.35)$ & 0.90 \\
\hline Positive reappraisal & 1 (reference) & $1.16(0.93-1.44)$ & $1.25(1.02-1.54)$ & 0.03 \\
\hline Problem solving & 1 (reference) & $0.97(0.76-1.24)$ & $1.15(0.91-1.46)$ & 0.03 \\
\hline Disengagement & 1 (reference) & $0.86(0.73-0.99)$ & $0.79(0.67-0.95)$ & 0.01 \\
\hline \multicolumn{5}{|l|}{ Women $(n=6,982)$} \\
\hline Perceived stress & 1 (reference) & $1.00(0.84-1.19)$ & $1.06(0.88-1.28)$ & 0.51 \\
\hline Emotion expression & 1 (reference) & $0.90(0.76-1.07)$ & $0.89(0.72-1.10)$ & 0.30 \\
\hline Emotional support seeking & 1 (reference) & $1.00(0.85-1.18)$ & $0.95(0.79-1.14)$ & 0.53 \\
\hline Positive reappraisal & 1 (reference) & $0.96(0.75-1.22)$ & $0.93(0.74-1.19)$ & 0.54 \\
\hline Problem solving & 1 (reference) & $0.91(0.72-1.15)$ & $0.99(0.79-1.24)$ & 0.60 \\
\hline Disengagement & 1 (reference) & $0.87(0.72-1.06)$ & $0.92(0.76-1.13)$ & 0.77 \\
\hline
\end{tabular}

${ }^{a}$ Adjusted for age, socio-economic status (occupation, working hours, and years of schooling), lifestyle factors (drinking, smoking, physical activity level, sleeping hours, and energy intake), and either perceived stress (for each of coping strategies) or all coping strategies (for perceived stress).

${ }^{\mathrm{b}} \mathrm{P}$ values for trend were estimated from multiple linear regression analysis including in the model an ordinal variable (1-3 assigned to low, medium, and high levels, respectively) for each of perceived stress and coping strategies.

doi:10.1371/journal.pone.0118105.t005 
Although these findings are not directly relevant to coping strategies, some gender-dependent responses of cortisol and other unknown mediators with coping strategies triggered by psychosocial stress might contribute to the male-specific associations between coping strategies and BMI in this study.

In stratified analyses, we found some differences by occupation in the above associations of problem solving and disengagement with BMI in men although the corresponding interactions were not significant. These associations were evident in professionals (categories $0-2$ ) and blue collar workers (categories 6-9), but not in white collar workers (categories 3-5) and unemployed subjects. We currently have no plausible explanations for this finding, and chance could be responsible. Unemployed subjects included retired and jobless people as well as housewives, who may have different significance in coping strategies. Unfortunately, we could not address the significance of heterogeneity in unemployed subjects due to the lack of relevant data.

It was also notable that the associations of problem solving and disengagement with BMI were modified by the level of perceived stress. To our knowledge, no studies have been conducted on this issue, but a few studies demonstrated that the relations of some coping strategies to high-sensitivity C-reactive protein [19] and depression [39] were dependent on the level of psychosocial stress. In this study, the positive association between problem solving and BMI and the inverse association between disengagement and BMI were more evident in higher levels of stress. This finding suggests that these coping strategies may play an important role in the increase or decrease of BMI, particularly among individuals with high stress levels. The lack of information on coping strategies in previous studies might have obscured true associations to some extent.

The strength of our study includes the large sample size and the detailed measures of SES and lifestyle factors as covariates. Meanwhile, several limitations should be mentioned. First, because we could not explicitly exclude subjects with mental illness, our findings may have been affected by some connection of perceived stress or coping strategies with relatively common mental illness (e.g., depression and anxiety disorders) [40]. Although we could not assess the prevalence of such mental illness, our study included 46 subjects ( $0.4 \%)$ with self-reported treatment for depression and 140 subjects (1.2\%) with self-reported medication of antipsychotics, antidepressants, and/or anxiolytics. Both prevalences were lower than those reported in Japan [41,42], suggesting that those mental illnesses may have been underrepresented in our study subjects. Second, we did not obtain information on detailed eating behaviors (e.g., eating binges [43], midnight snack intake, and the time of eating, especially of dinner). Thus, we could not exclude the possibility that such eating behaviors might have mediated the association between some coping strategy and BMI although we excluded subjects with an extreme energy intake ( $>4000 \mathrm{kcal} /$ day) and adjusted for energy intake. In particular, eating binges is one of the important stress coping behaviors, which is observed more frequently women [43]. In our female subjects, however, the lack of any significant associations between coping strategies and BMI after adjustment for age only (Table 3) suggests the absence of important mediators including eating binges, at least in this study. Third, perceived stress and coping strategies were evaluated by using simple questions. For coping strategies, the poor to fair reproducibility (weighted $\kappa 0.30-0.55)[19,44]$ may have weakened true associations. Fourth, our results on coping strategies and BMI may not be regarded as causal relationships due to the cross-sectional design. Finally, the study subjects consisted of only the Japanese, so our results may not be generalized to other ethnicities with different psychosocial backgrounds.

In conclusion, we found that lower levels of disengagement and higher levels of positive reappraisal and problem solving were independent predictors of increased BMI and overweight/ obesity in Japanese middle-aged and older men. Our findings suggest that some coping strategies may have an important role in developing obesity, so we recommend that future studies 
should assess the risk of obesity related to psychosocial stress, with taking into account the influence of coping strategies.

\section{Author Contributions}

Conceived and designed the experiments: CS M. Hara YH KS KT. Performed the experiments: M. Horita YH. Analyzed the data: CS M. Hara HN KT. Wrote the paper: CS KT. Data acquisition: CS M. Hara YN HN YO KN YH TI NT TS KS KT.

\section{References}

1. Rosengren A, Hawken S, Ounpuu S, Sliwa K, Zubaid M, et al. (2004) Association of psychosocial risk factors with risk of acute myocardial infarction in 11119 cases and 13648 controls from 52 countries (the INTERHEART study): case-control study. Lancet 364: 953-962. PMID: 15364186

2. Kivimäki M, Nyberg ST, Batty GD, Fransson El, Heikkilä K, et al. (2012) Job strain as a risk factor for coronary heart disease: a collaborative meta-analysis of individual participant data. Lancet 380: 1491-1497. doi: 10.1016/S0140-6736(12)60994-5 PMID: 22981903

3. Jiang J, Ahn J, Huang WY, Hayes RB (2013) Association of obesity with cardiovascular disease mortality in the PLCO trial. Prev Med 57: 60-64. doi: 10.1016/j.ypmed.2013.04.014 PMID: 23632233

4. Wardle J, Chida Y, Gibson EL, Whitaker KL, Steptoe A (2011) Stress and adiposity: a meta-analysis of longitudinal studies. Obesity (Silver Spring) 19: 771-778. doi: 10.1038/oby.2010.241 PMID: 20948519

5. Nyberg ST, Fransson El, Heikkilä K, Alfredsson L, Casini A, et al. (2013) Job strain and cardiovascular disease risk factors: meta-analysis of individual-participant data from 47,000 men and women. PLoS One 8: e67323. doi: 10.1371/journal.pone.0067323 PMID: 23840664

6. Harding JL, Backholer K, Williams ED, Peeters A, Cameron AJ, et al. (2013) Psychosocial stress is positively associated with body mass index gain over 5 years: Evidence from the longitudinal AusDiab study. Obesity (Silver Spring) 22: 277-286.

7. Block JP, He Y, Zaslavsky AM, Ding L, Ayanian JZ (2009) Psychosocial stress and change in weight among US adults. Am J Epidemiol 170: 181-192. doi: 10.1093/aje/kwp104 PMID: 19465744

8. Kouvonen A, Kivimäki M, Cox SJ, Cox T, Vahtera J (2005) Relationship between work stress and body mass index among 45,810 female and male employees. Psychosom Med 67: 577-583. PMID: 16046370

9. Lazarus RS (1984) Puzzles in the study of daily hassles. J Behav Med 7: 375-389. PMID: 6520869

10. Taylor SE, Stanton AL (2007) Coping resources, coping processes, and mental health. Annu Rev Clin Psychol 3: 377-401. PMID: 17716061

11. Dallman MF, la Fleur SE, Pecoraro NC, Gomez F, Houshyar H, et al. (2004) Minireview: glucocorticoids-food intake, abdominal obesity, and wealthy nations in 2004. Endocrinology 145: 2633-2638. PMID: 15044359

12. Rueggeberg R, Wrosch C, Miller GE, McDade TW (2012) Associations between health-related selfprotection, diurnal cortisol, and C-reactive protein in lonely older adults. Psychosom Med 74: 937-944. doi: 10.1097/PSY.0b013e3182732dc6 PMID: 23115346

13. O'Donnell K, Badrick E, Kumari M, Steptoe A (2008) Psychological coping styles and cortisol over the day in healthy older adults. Psychoneuroendocrinology 33: 601-611. doi: 10.1016/j.psyneuen.2008. 01.015 PMID: 18329182

14. Strickland OL, Giger JN, Nelson MA, Davis CM (2007) The relationships among stress, coping, social support, and weight class in premenopausal African American women at risk for coronary heart disease. J Cardiovasc Nurs 22: 272-278. PMID: 17589278

15. Wakai K, Hamajima N, Okada R, Naito M, Morita E, et al. (2011) Profile of participants and genotype distributions of 108 polymorphisms in a cross-sectional study of associations of genotypes with lifestyle and clinical factors: a project in the Japan Multi-Institutional Collaborative Cohort (J-MICC) Study. J Epidemiol 21: 223-235. PMID: 21467728

16. Hamajima N, Group J-MS (2007) The Japan Multi-Institutional Collaborative Cohort Study (J-MICC Study) to detect gene-environment interactions for cancer. Asian Pac J Cancer Prev 8: 317-323. PMID: 17696755

17. Hara M, Higaki Y, Imaizumi T, Taguchi N, Nakamura K, et al. (2010) Factors influencing participation rate in a baseline survey of a genetic cohort in Japan. J Epidemiol 20: 40-45. PMID: 19897942 
18. Nanri H, Nakamura K, Hara M, Higaki Y, Imaizumi T, et al. (2011) Association between dietary pattern and serum C-reactive protein in Japanese men and women. J Epidemiol 21: 122-131. PMID: 21325731

19. Shimanoe C, Otsuka Y, Hara M, Nanri H, Nishida Y, et al. (2014) Gender-specific associations of perceived stress and coping strategies with $\mathrm{C}$-reactive protein in middle-aged and older men and women. Int J Behav Med 21: 821-832. doi: 10.1007/s12529-013-9341-y PMID: 24085705

20. Iso H, Date C, Yamamoto A, Toyoshima H, Tanabe N, et al. (2002) Perceived mental stress and mortality from cardiovascular disease among Japanese men and women: the Japan Collaborative Cohort Study for Evaluation of Cancer Risk Sponsored by Monbusho (JACC Study). Circulation 106: 1229-1236. PMID: 12208798

21. Sasaki M, Yamasaki K (2002) [Development of a dispositional version of the General Coping Questionnaire (GCQ) and examination of its reliability and validity]. Nihon Koshu Eisei Zasshi 49: 399-408 (in Japanese). PMID: 12087766

22. Sasaki M, Kitaoka-Higashiguchi K, Morikawa $Y$, Nakagawa $H(2009)$ Relationship between stress coping and burnout in Japanese hospital nurses. J Nurs Manag 17: 359-365. PMID: 21456321

23. Carver CS (1997) You want to measure coping but your protocol's too long: consider the brief COPE. Int J Behav Med 4: 92-100. PMID: 16250744

24. Kumahara H, Schutz Y, Ayabe M, Yoshioka M, Yoshitake $Y$, et al. (2004) The use of uniaxial accelerometry for the assessment of physical-activity-related energy expenditure: a validation study against whole-body indirect calorimetry. Br J Nutr 91: 235-243. PMID: 14756909

25. Health Promotion and Nutrition Division HSB, Ministry of Health and Welfare of Japan (1994) Fifth Revision of the Recommended Dietary Allowances for Japanese. Tokyo: Daiichi Syuppan (in Japanese).

26. Fujimoto S, Watanabe T, Sakamoto A, Yukawa K, Morimoto K (1968) [Studies on the physical surface area of Japanese. 18. Calculation formulas in three stages over all ages]. Nihon Eiseigaku Zasshi 23: 443-450 (in Japanese). PMID: 5752712

27. Tokudome S, Goto C, Imaeda N, Tokudome Y, Ikeda M, et al. (2004) Development of a data-based short food frequency questionnaire for assessing nutrient intake by middle-aged Japanese. Asian Pac J Cancer Prev 5: 40-43. PMID: 15075003

28. Tokudome Y, Goto C, Imaeda N, Hasegawa T, Kato R, et al. (2005) Relative validity of a short food frequency questionnaire for assessing nutrient intake versus three-day weighed diet records in middleaged Japanese. J Epidemiol 15: 135-145. PMID: 16141632

29. Science Japan and Agency Technology (2000) Standard Tables of Food Composition in Japan, Fifth Revised Edition. Tokyo: Ministry of Finance Printing Bureau (in Japanese). PMID: 15526759

30. WHO (2000) Obesity: preventing and managing the global epidemic. Report of a WHO consultation. World Health Organ Tech Rep Ser 894: i-xii, 1-253. PMID: 11234459

31. Yang TC, Matthews SA, Chen VY (2014) Stochastic variability in stress, sleep duration, and sleep quality across the distribution of body mass index: insights from quantile regression. Int J Behav Med 21: 282-291. doi: 10.1007/s12529-013-9293-2 PMID: 23385490

32. Wardle J, Steptoe A, Oliver G, Lipsey Z (2000) Stress, dietary restraint and food intake. J Psychosom Res 48: 195-202. PMID: 10719137

33. Barrington WE, Ceballos RM, Bishop SK, McGregor BA, Beresford SA (2012) Perceived stress, behavior, and body mass index among adults participating in a worksite obesity prevention program, Seattle, 2005-2007. Prev Chronic Dis 9: E152 doi: 10.5888/pcd9.120001 PMID: 23036611

34. Rosmond R (2005) Role of stress in the pathogenesis of the metabolic syndrome. Psychoneuroendocrinology 30: 1-10. PMID: 15358437

35. Carver CS, Connor-Smith J (2010) Personality and coping. Annu Rev Psychol 61: 679-704. doi: 10. 1146/annurev.psych.093008.100352 PMID: 19572784

36. Martin LA, Critelli JW, Doster JA, Powers C, Purdum M, et al. (2013) Cardiovascular risk: gender differences in lifestyle behaviors and coping strategies. Int J Behav Med 20: 97-105. doi: 10.1007/s12529011-9204-3 PMID: 22144263

37. Eller NH, Netterstrøm B, Hansen AM (2006) Psychosocial factors at home and at work and levels of salivary cortisol. Biol Psychol 73: 280-287. PMID: 16824664

38. Steptoe A, Siegrist J, Kirschbaum C, Marmot M (2004) Effort-reward imbalance, overcommitment, and measures of cortisol and blood pressure over the working day. Psychosom Med 66: 323-329. PMID: 15184690

39. Wei-Qing C, Oi-Ling S, Jia-Fang L, Cooper CL, Phillips DR (2009) Work stress and depression: the direct and moderating effects of informal social support and coping. Stress \& Health: Journal of the International Society for the Investigation of Stress 25: 431-443. 
40. Kelly SJ, Daniel M, Dal Grande E, Taylor A (2011) Mental ill-health across the continuum of body mass index. BMC Public Health 11: 765 doi: 10.1186/1471-2458-11-765 PMID: 21975214

41. Nakagawa A (2011) Ministry of Health, Labour and Welfare. Research Database: Report of Ministry of Health, Labour Science Research Grant Special Research, International Comparison of Psychotropic Medication Prescription Patterns (in Japanese). Available: http://mhlw-grants.niph.go.jp/niph/search/ NIDD00.do? resrchNum=201005018A. Accessed 4 November 2014

42. Kawakami N, Takeshima T, Ono Y, Uda H, Hata Y, et al. (2005) Twelve-month prevalence, severity, and treatment of common mental disorders in communities in Japan: preliminary finding from the World Mental Health Japan Survey 2002-2003. Psychiatry Clin Neurosci 59: 441-452. PMID: 16048450

43. Nicdao EG, Hong S, Takeuchi DT (2007) Prevalence and correlates of eating disorders among Asian Americans: results from the National Latino and Asian American Study. Int J Eat Disord 40 Suppl: S22-26. PMID: 17879986

44. Landis JR, Koch GG (1977) The measurement of observer agreement for categorical data. Biometrics 33: 159-174. PMID: 843571 